OPEN ACCESS

Edited by:

José E. Barboza-Corona,

University of Guanajuato, Mexico

Reviewed by:

Peilong Yang,

Chinese Academy of Agricultural

Sciences, China

Yingguo Bai,

Feed Research Institute (CAAS),

China

${ }^{*}$ Correspondence:

Jianren Ye

njfu_jrye@163.com;

jrye@njfu.edu.cn

Specialty section:

This article was submitted to Microbiotechnology, Ecotoxicology,

and Bioremediation,

a section of the journal

Frontiers in Microbiology

Received: 15 October 2019

Accepted: 26 December 2019

Published: 22 January 2020

Citation:

Chen F, Ye J,

Sista Kameshwar AK, Wu X, Ren J,

Qin W and Li D-W (2020) A Novel Cold-Adaptive Endo-1,4- $\beta$-Glucanase

From Burkholderia pyrrocinia

JK-SH007: Gene Expression and Characterization of the Enzyme and Mode of Action.

Front. Microbiol. 10:3137. doi: 10.3389/fmicb.2019.03137

\section{A Novel Cold-Adaptive Endo-1,4- $\beta$-Glucanase From Burkholderia pyrrocinia JK-SH007: Gene Expression and Characterization of the Enzyme and Mode of Action}

\author{
Feifei Chen ${ }^{1,2}$, Jianren Ye ${ }^{1 *}$, Ayyappa Kumar Sista Kameshwar ${ }^{2}$, Xuelian Wu ${ }^{1}$, \\ Jiahong Ren ${ }^{3}$, Wensheng Qin' ${ }^{2}$ and De-Wei Li ${ }^{1,4}$
}

1 Jiangsu Key Laboratory for Prevention and Management of Invasive Species, Co-innovation Center for Sustainable Forestry in Southern China, College of Forestry, Nanjing Forestry University, Nanjing, China, ${ }^{2}$ Department of Biology, Lakehead University, Thunder Bay, ON, Canada, ${ }^{3}$ Department of Biology Science and Technology, Changzhi College, Changzhi, China, ${ }^{4}$ The Connecticut Agricultural Experiment Station, Valley Laboratory, Windsor, CT, United States

The efficient industrial conversion of plant-derived cellulose to simple sugars and other value-added chemicals requires various highly stable and reactive enzymes. Industrial processes especially synchronous saccharification and fermentation (SSF)based production of cellulosic bio-ethanol require enzymes that are active at lower temperatures. In this study, we have identified, characterized, and expressed the cold-adaptive endo-1,4- $\beta$-glucanase (BpEG) isolated from the Burkholderia pyrrocinia $\mathrm{JK}-\mathrm{SH} 007$. The analysis of the predicted amino acid sequence indicated that BpEG belongs to $\mathrm{GH}$ family 8 . The $B p E G$ without the signal peptide was cloned into the expression vector pET32a and significantly expressed in Escherichia coli BL21 (DE3) competent cells. The SDS-PAGE and Western blot analysis of BpEG revealed that the recombinant BpEG was approximately $60 \mathrm{kDa}$. Purified recombinant BpEG exhibited hydrolytic activity against carboxymethyl cellulose (CMC) and phosphoric acid swollen cellulose (PASC), but not crystalline cellulose and xylan substrates. High performance, anion exchange, chromatography-pulsed amperometric detector (HPAEC-PAD) analysis of the enzymatic products obtained from depolymerization of $1,4-\beta$-linked biopolymers of different lengths revealed an interesting cutting mechanism employed by endoglucanases. The recombinant BpEG exhibited 6.0 of optimum $\mathrm{pH}$ and $35^{\circ} \mathrm{C}$ of optimum temperature, when cultured with $\mathrm{CMC}$ substrate. The BpEG enzyme exhibited stable activity between $\mathrm{pH} 5.0$ and 9.0 at $35^{\circ} \mathrm{C}$. Interestingly, BpEG retained about $42 \%$ of its enzymatic activity at $10^{\circ} \mathrm{C}$ compared to its optimal temperature. This new cold-adaptive cellulase could potentially achieve synchronous saccharification and fermentation (SSF) making BpEG a promising candidate in the fields of biofuel, biorefining, food and pharmaceutical industries.

Keywords: cloning, expression, GC-rich gene, endo-1,4- $\beta$-glucanase, Burkholderia pyrrocinia, cold-adaptive enzyme 


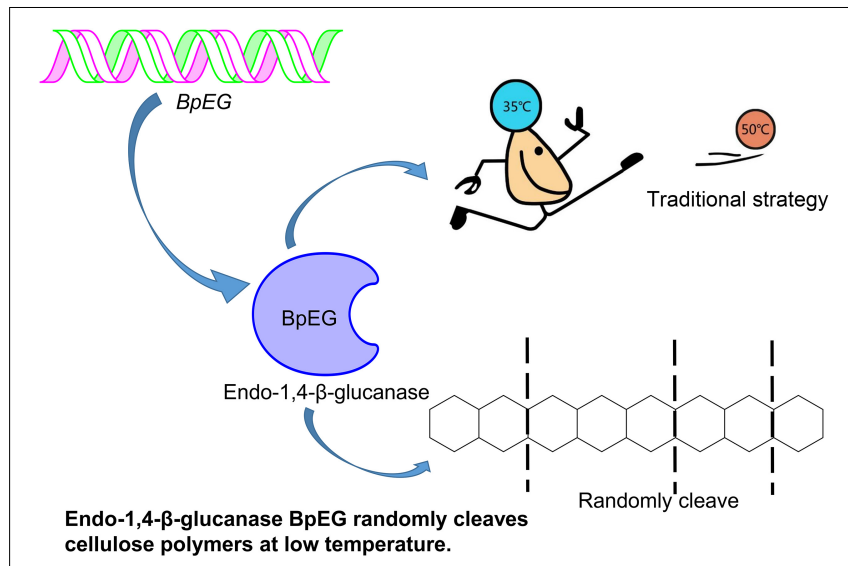

GRAPHICAL ABSTRACT | BpEG randomly cleaves cellulose polymers in low temperature.

\section{INTRODUCTION}

Increasing global population and continuous depletion of fossil fuels worldwide have forced the search for renewable fuel alternatives (Zhao et al., 2011; Rafique and Rehman, 2017). Incipient cellulosic-ethanol production methods based on food crops like corn played a certain but short-term role. However, the food versus fuel debate and continuously increasing demand for food supplies around the world lead to second-generation fuels. Although the second-generation fuels overcame the disadvantages of first-generation fuels by using cheaper, non-food crops as the substrate for fuel production, the usage of fertile land to produce energy crops is a significant obstacle. These disadvantages have led to the development of promising third- and fourth-generation biofuels that use wood, agricultural, algal residues, and other new technologies based on the simultaneous conversion of carbon dioxide (Balat, 2011).

Cellulose is one of the major components of plant biomass (lignocellulose), one of the most abundant organic components in nature, and a remarkable renewable energy resource (Heinze et al., 2018). Efficient breakdown and conversion of complex cellulose into simple glucose is a crucial process in biofuel generation and yet a major hurdle in the production of cellulosic ethanol. Many bacterial and fungal strains secrete highly catalytic cellulases, which efficiently break down the $1,4-\beta$-glycosidic linkages of cellulose resulting in linear polymers of hydro glucopyranoses (Bianchetti et al., 2013; Wang et al., 2014). In nature, enzymatic hydrolysis of cellulose to glucose is a complicated process, because of its rigid and harsh structure which requires a synergistic action of cellulolytic

Abbreviations: Bcc, Burkholderia cepacia complex; BpEG, endo-1,4- $\beta$-glucanase from Burkholderia pyrrocinia JK-SH007; CBB, coomassie brilliant blue; CMC, carboxymethyl cellulose; dNTP, deoxynucleotide triphosphate; HPAEC-PAD, high performance anion exchange chromatography-pulsed amperometric detector; IPTG, isopropylthio- $\beta$-D-galactopyranoside; PASC, phosphoric acid swollen cellulose; SDS-PAGE, sodium dodecyl sulfate-polyacrylamide gel electrophoresis; SSF, synchronous saccharification and fermentation; WB, Western blot. enzymes including exo- $\beta$-1,4-glucanases (EC3.2.1.91), endo- $\beta$-1,4-glucanases (EC3.2.1.4), and $\beta$-glucosidases (EC 3.2.1.21) (Sharma et al., 2016). Firstly, glucose and cellobiose are released from the terminals of cellulose polymers by exo$\beta$-1,4-glucanases (EC3.2.1.91). Secondly, the internal structures of the biopolymers connected through 1,4- $\beta$-glycosidic bonds are converted to cello-oligosaccharides of assorted lengths by endo- $\beta$-1,4-glucanases (EC3.2.1.4) by exhibiting a random degradation pattern (Park and Yun, 1999). Finally, the 1,4$\beta$-glucosidase (EC3.2.1.21) produces glucose from its cleavage of cello-oligosaccharides. Among these enzymes, endo- $\beta-1,4-$ glucanase (EC 3.2.1.4) is extremely important as it cleaves the $\beta$-1,4-glycosidic bonds of cellulose and generates cellooligosaccharides of random length (Huang et al., 2016). Thus, several studies have been conducted to develop and characterize recombinant endo- $\beta$-1,4-glucanases from various microbial sources. In particular, the endo- $\beta-1,4$-glucanases active at lower temperatures could potentially be of higher importance industrially, offering low energy processes that are both cost and time-efficient.

The industrial process of converting lignocellulosic plant biomass to a biofuel substrate primarily involves pretreatment for removing lignin (Uppugundla et al., 2014), enzymatic hydrolysis of cellulose into sugar (Silveira et al., 2014), and ethanol fermentation using yeasts (Wu et al., 2016). Conversion of cellulose to bioethanol is a two-step process: saccharification and fermentation, respectively. The saccharification process is conducted at higher temperatures between 50 and $55^{\circ} \mathrm{C}$ (which requires high energy and cost) (Murashima et al., 2002; Wang et al., 2009; Liu et al., 2016), while the ethanol fermentation using Saccharomyces cerevisiae occurs at lower temperatures between 25 and $30^{\circ} \mathrm{C}$ (Borrull et al., 2016; Reis et al., 2018). Thus a cold-adaptive, endo- $\beta$-1,4-glucanase catalyzing the saccharification process under ambient temperatures could be of high significance. According to the report of Khalili Ghadikolaei et al. (2018), the endo- $\beta$-1,4-glucanases active under lower temperatures can enhance various industrial applications including paperpulp processing, biofuel, food and feedstock, textile, laundry, and pharmaceutical industries (Khalili Ghadikolaei et al., 2018). Exploration of cold-adaptive cellulases provides a great potential to achieve synchronous saccharification and fermentation (SSF).

Research and applications of cold-active enzymes from Burkholderia have paved the way for our current study. A cold-active lipase isolated from Burkholderia sp. (SYBC LIP-Y) was characterized and overexpressed, which exhibited higher catalytic activities at lower temperatures (Yuan et al., 2010). Similar studies conducted by Jin et al. has reported an efficient cold-adapted lipase (LIP$\mathrm{BA})$ isolated from the Burkholderia anthina NT15, which exhibited higher catalytic activities even at lower temperatures (Jin et al., 2012). However, the study of endo-1,4- $\beta$-glucanase from Burkholderia is limited. To explore cold-adaptive cellulases could potentially achieve synchronous saccharification and fermentation (SSF). Thus, we report the heterologous expression of a novel 
cold-adaptive endo-1,4- $\beta$-glucanase gene isolated from Burkholderia pyrrocinia.

\section{MATERIALS AND METHODS}

\section{Bioinformatic Analysis}

We have performed an automated NCBI Blastn and Blastx protein homology analysis using the sequence fragment which is annotated as an endo-1,4- $\beta$-glucanase from the whole genome sequence of the B. pyrrocinia JK-SH007 strain (as sequenced by Beijing Genomics Institute-BGI), and we further named the sequence fragment as $B p E G$. The BpEG amino acid sequence retrieved from the B. pyrrocinia JK-SH007 strain was aligned with the GH8 family proteins downloaded from the NCBI database using the ClustalW program. The signal peptide analysis of BpEG was performed using the SignalP 4.0 server website ${ }^{1}$. The above-obtained BpEG amino acid sequences were subjected to 3D homology modeling analysis using SWISS-MODEL online web-database and PC version software (SPDBV_4.10_PC). The homology modeling of BpEG was achieved using PDB (protein data bank) template protein with accession ID 3qxq.1.

\section{Cloning of the BpEG Gene}

The full-length $B p E G$ gene sequence was retrieved from the genomic DNA of B. pyrrocinia JK-SH007 using the designed forward (5'-ATGGCGAAGCGACGGGTAACG-3') and reverse (5'-TCAGCGGGCGGCGCACGAAGG-3') primers. The BpEG gene sequence we obtained (described above) was amplified using a PCR machine with the PCR reaction mixture containing B. pyrrocinia DNA (50-100 ng), $0.1 \mu \mathrm{M}$ the specific primer, $80 \mu \mathrm{M}$ dNTP, $0.5 \mathrm{U}$ LA Taq and $10 \mu \mathrm{L} 2 \times$ GC buffer II (Takara Bio, Dalian, China). The PCR reaction was performed using the following conditions: $95^{\circ} \mathrm{C}$ for $10 \mathrm{~min}$, thermocycling consisted of 33 cycles at $95^{\circ} \mathrm{C}$ for $10 \mathrm{~s}, 60^{\circ} \mathrm{C}$ for $10 \mathrm{~s}$, and $72^{\circ} \mathrm{C}$ for $90 \mathrm{~s}$, with a final extension at $72^{\circ} \mathrm{C}$ for $10 \mathrm{~min}$. The PCR products were analyzed using $1 \%$ agarose gel. The resulting $1.2-\mathrm{kb}$ DNA fragment was purified and cloned into a $\mathrm{pMD}^{\mathrm{TM}} 19-\mathrm{T}$ vector (Takara Bio, Dalian, China) thus, the obtained BpEG gene was subjected to DNA sequencing.

\section{Construction of the Expression Plasmid}

The $B p E G$ gene fragment without the signal peptide coding sequence was amplified using the custom-designed forward (5'-TGAATTCCGCGCGCAGGCCGCGGGCGCC-3', EcoRI site underlined) and reverse (5'-CAAGCTTTCAGCGGG CGGCGCACGAAGG-3', HindIII site) PCR primers. The PCR primers were synthesized in the regions corresponding to amino acid residues 33-39 and 399-405 of BpEG, respectively. The PCR reaction mixture (total of $20 \mu \mathrm{L}$ Prime STAR buffer) contained B. pyrrocinia JK-SH007 DNA, $0.1 \mu \mathrm{M}$ of each primer, $80 \mu \mathrm{M}$ of each dNTP, $0.5 \mathrm{U}$ of Takara PrimeSTAR DNA polymerase and PrimeSTAR GC buffer (Takara Bio, Dalian, China). The PCR cycle was set up for 33 cycles at $95^{\circ} \mathrm{C}$ for $30 \mathrm{~s}, 60^{\circ} \mathrm{C}$ for $30 \mathrm{~s}$, and $72^{\circ} \mathrm{C}$ for $90 \mathrm{~s}$, thus obtained PCR

${ }^{1}$ http://www.cbs.dtu.dk/services/SignalP-4.0/ products were analyzed using $1 \%$ agarose gel. The resulting 1.1-kb DNA fragment was cloned into the $\mathrm{pMD}^{\mathrm{TM}} 19-\mathrm{T}$ vector by following the manufacturer's instructions. The cloning vector $\left(B p E G-\mathrm{pMD}^{\mathrm{TM}} 19-\mathrm{T}\right)$ containing the DNA fragment and expression vector (pET32a) were treated with the restriction enzymes EcoRI and HindIII. The DNA fragments of BpEG and linearized pET32a vector carrying a thioredoxin- $6 \times$ His-tag were mixed and ligated with T4 DNA ligase (Takara Bio, Dalian, China). The expression plasmid coding a mature $B p E G$ was named pET32a-BpEG and was transformed into Escherichia coli JM109 competent cells. The transformed colonies were evaluated using colony PCR followed by sequencing the BpEG gene.

\section{Heterologous Expression of Recombinant BpEG}

The recombinant pet32a-BpEG expression plasmid carrying a thioredoxin- $6 \times$ His-tag was transformed into E. coli BL21 (DE3) competent cells. The transformed bacterium was cultured in $100 \mathrm{~mL} \mathrm{LB}$ medium with $100 \mu \mathrm{g} / \mathrm{mL}$ ampicillin at $37^{\circ} \mathrm{C}$. The transformed bacterium was cultured until it reached an optical density of 0.6 at $600 \mathrm{~nm}$, respectively. Expression of the recombinant BpEG containing the thioredoxin- $6 \times$ His-tag was induced with $0.5 \mathrm{mM}$ IPTG by incubating at $16^{\circ} \mathrm{C}$ overnight. Later, the bacterial cells were harvested using centrifugation at $10,000 \times g$ for $20 \mathrm{~min}$ at $4^{\circ} \mathrm{C}$. The above-obtained cells were resuspended in $10 \mathrm{~mL}$ of $20 \mathrm{mM}$ Tris- $\mathrm{HCl}$ buffer $(\mathrm{pH} 7.0)$ containing a serine protease inhibitor (PMSF), sonicated, and centrifuged at $10,000 \times g$ for $20 \mathrm{~min}$ at $4^{\circ} \mathrm{C}$. The supernatant was applied to a His GraviTrap with Ni-IDA and equilibrated using $20 \mathrm{mM}$ phosphate buffer ( $\mathrm{pH}$ 8.0) containing $20 \mathrm{mM}$ imidazole and $300 \mathrm{mM} \mathrm{NaCl}$. BpEG was eluted over $20-300 \mathrm{mM}$ imidazole gradient at gravity flow. The active fractions were desalted and concentrated on an Amicon ${ }^{\circledR}$ Ultra-15 centrifugal filter device that was equilibrated with $20 \mathrm{mM}$ sodium acetate buffer containing $100 \mathrm{mM} \mathrm{NaCl}$ at $\mathrm{pH}$ 5.0. The enzyme was eluted using $20 \mathrm{mM}$ Tris- $\mathrm{HCl}(\mathrm{pH}$ 7.0) to obtain a purified enzyme solution.

\section{SDS-PAGE and Western Blot Analysis}

The molecular weight of the purified recombinant BpEG was determined using $12.5 \%$ sodium dodecyl sulfate-polyacrylamide gel electrophoresis (SDS-PAGE) (Laemmli, 1970) using the Opti-Protein Marker/Ladder (Applied Biological Materials, Inc., Canada). Protein bands were detected using Coomassie Brillant Blue (CBB) R-250 staining. The expression of BpEG protein samples was characterized using Western blotting with the standard protocols (Laemmli, 1970; Towbin et al., 1979). The purified BpEG protein was also loaded on to $12.5 \%$ sodium dodecyl sulfate-polyacrylamide gel electrophoresis (SDS-PAGE) and electroblotted for $1 \mathrm{~h}$ onto the polyvinylidene fluoride (PVDF) membrane in a Tris-glycine-methanol buffer. After, the membrane was incubated in a $1 \%$ bovine serum albumin (BSA) solution overnight and later probed with $6 \times$ His-tag antibodies at 1:1,000 dilutions and a rabbit Anti-Mouse IgG (H\&L) APconjugated with alkaline phosphatase was used as the secondary antibody at a dilution of 1:7,500 (Promega, United States). 
Chromogenic detection of BpEG protein bands was performed using western blue, a stabilized substrate for alkaline phosphatase (Promega, United States), and the reaction was later stopped by rinsing with water.

\section{Partial Peptide Fragment Sequence}

To further identify the purified enzyme, the single band was cut out from the gel and digested with trypsin. The protein products were further analyzed and characterized using a liquid chromatography-electrospray, ionization-tandem mass spectrometry (LC-ESI-MS/MS). We have used an automated protein sequencer to determine the partial amino acid sequence of the BpEG peptide (Ueda et al., 2008).

\section{Enzyme and Protein Assay}

The activity of BpEG was determined using the standard 3,5dinitrosalicylic acid (DNS) method by determining the reduced sugars released from CMC and PASC substrates. The above reactions were continuously monitored at an absorbance of $540 \mathrm{~nm}$ (Miller, 1959). The one unit of endo-1,4- $\beta$-glucanase activity is determined as the enzyme required to produce the amount of reducing sugar equal to $1 \mu \mathrm{mol}$ of glucose per min of reaction time. The protein concentration of $\mathrm{BpEG}$ was quantified using the BCA Protein Assay Kit. The whole experiment was conducted in triplicate (both the reaction and its control samples).

\section{Effects of pH and Temperature on BpEG Activity and Stability}

The enzymatic activity of recombinant BpEG was determined using CMC (substrate) at a wide range of $\mathrm{pH}$ and temperatures. The optimal temperature required for recombinant BpEG was determined by culturing at a wide range of temperatures between 10 and $60^{\circ} \mathrm{C}$ with $5^{\circ} \mathrm{C}$ intervals, respectively. The effect of $\mathrm{pH}$ on enzyme activity was measured by culturing at different $\mathrm{pH}$ ranging between $\mathrm{pH} 3.0$ and 11 with the temperature set at $35^{\circ} \mathrm{C}$ for $30 \mathrm{~min}$. The $\mathrm{pH}$ stability of BpEG was determined by incubating the $\mathrm{BpEG}$ at $35^{\circ} \mathrm{C}$ for $30 \mathrm{~min}$ using $0.1 \mathrm{M}$ of the following buffer solutions: sodium citrate $(\mathrm{pH} 3.0-6.0)$, sodium phosphate ( $\mathrm{pH} 6.0-8.0)$, and glycine- $\mathrm{NaOH}(\mathrm{pH} 9.0-$ 11.0). Similarly, the temperature stability of the BpEG was determined by incubating in $0.1 \mathrm{M}$ sodium citrate $(\mathrm{pH} 6.0$ ) for 15-45 min at various temperatures ranging from 1 to $60^{\circ} \mathrm{C}$. These experiments were conducted using the protocol reported by Ueda et al. (2014). The amount of reducing sugars produced by these reactions was further measured using the standard 3,5dinitrosalicylic acid (DNS) method as described above (Miller, 1959). All the experiments were conducted in triplicates.

\section{Substrate Specificity}

The substrate specificity of BpEG was determined by using the $\beta$-glycosidic bonds containing polymers such as microcrystalline cellulose (Avicel), PASC (Schulein, 1997), xylan, and CMC. The enzyme activity of BpEG was measured using the standard 3,5dinitrosalicylic acid (DNS) method as described above (Miller, 1959) by calculating the amount of reducing sugars produced.

\section{HPAEC-PAD Analysis}

The mode of action of the BpEG enzyme was determined using high-performance anion exchange chromatography equipped with a pulsed amperometric detector (HPAEC-PAD). The reaction mixture contained $0.1 \mathrm{M}$ acetate buffer ( $\mathrm{pH}$ 6.0) with $10 \mu \mathrm{L}$ enzyme and $1 \mathrm{mgmL}^{-1}$ of $1,4-\beta$-linked CMC and oligosaccharides (CMC, cellopentaose, cellotetraose, or cellotriose). The reaction was carried out at $35^{\circ} \mathrm{C}$, and the samples were collected after $24 \mathrm{~h}$ and further characterized by HPAECPAD as previously described by Xu et al. (2013).

\section{The Potential Application of BpEG}

The potential application of BpEG was explored by degrading different biomass, which included wheat bran, oat grain, and ginkgo leaves. All the biomass was dried in an oven at $65^{\circ} \mathrm{C}$ till constant weight obtained and grounded in the mortar. Then the biomass was separated through the 0.149 millimeters sieve (100 series). In order to remove the background effects, the biomass was washed 5 times by using hot water at $65^{\circ} \mathrm{C}$. The amount of reducing sugars produced by these reactions was measured using the standard 3,5-dinitrosalicylic acid (DNS) method, as described above (Miller, 1959). Determination of reducing sugars was performed under optimal conditions. All the experiments were conducted in triplicates.

\section{Statistical Analysis}

The data was processed and analyzed using Origin 8.0 software while the image processing and layout was done using the Adobe illustrator CC 2017 software.

\section{Nucleotide Sequence Accession Number}

The complete sequence of the endo-1,4- $\beta$-glucanase gene $(B p E G)$ from $B$. pyrrocinia JK-SH007 is reported in the present paper and has been deposited in the NCBI database under the NCBI accession number MH733823.

\section{RESULTS AND DISCUSSION}

We have reported the isolation and characterization of the B. pyrrocinia JK-SH007 strain from the stems of Populus deltoids. This bacterium was characterized using the 16S rDNA sequence analysis, recA gene sequence analysis combined with morphological, physiological, biochemical characteristics, and the Biolog ${ }^{\circledR}$ identification system, which revealed the isolated B. pyrrocinia JK-SH007 strain as part of the Bcc (Ren et al., 2011). In the present study, we identified, cloned and expressed the extrinsic endo-1,4- $\beta$-glucanase gene isolated from the B. pyrrocinia JK-SH007 strain.

\section{Cloning and Sequence Analysis of BpEG}

The protein sequence homology analysis based on NCBI Blastx and Blastn resulted in an ideal candidate exhibiting the highest similarity for endo-1,4- $\beta$-glucanase and we named the DNA sequence fragment as $B p E G$. Further sequence-based SignalP analysis revealed that $\mathrm{BpEG}$ has a signal peptide with 32 
amino acid residues at the $\mathrm{N}$-terminus. Moreover, the gene sequence analysis showed that the BpEG gene contains an open reading frame (ORF) of 1,218 nucleotides capable of encoding a polypeptide of 405 amino acids. The high percentage of $\mathrm{G}$ and $\mathrm{C}(74.71 \% \mathrm{GC})$ nucleotides in $B p E G$ sequence was the major challenge in conducting the gene cloning experiment. This could be one of the reasons for the absence of Burkholderia endo-1,4- $\beta$-glucanase gene cloning reports. The complete $B p E G$ gene sequence was deposited in the GenBank database with the accession number MH733823.

The sequence similarity analysis showed that BpEG displayed similarity with the endo-1,4- $\beta$-glucanase of Burkholderia stabilis (97\%; WP_096470653), Burkholderia cenocepacia (92\%; WP_053524826), and Burkholderia contaminans (92\%; WP_046545415). These Burkholderia 1,4- $\beta$-glucanases all belonging to the glycoside hydrolase $(\mathrm{GH})$ family 8 suggest that BpEG might also belong to the GH 8 family. Six strictly conserved residues of GH8 Glu 83, Asp144, Pro209, Trp230, Glu271, and $\operatorname{Arg} 278$ (Figure 1) were found in the catalytic module of BpEG according to the multiple sequence alignment (Figure 2) as described by Adachi et al. (2004) and Na et al. (2015). The amino acids sequencing analysis of BpEG using the ClustalW program revealed the conservative motif ASDADLWIAYALVEAGRLW (Figure 2).

The tentative 3-D homology model of BpEG developed using the SwissDock automated server showed that the BpEG structure encompasses a catalytic domain and a signal peptide like that of the endo-1,4- $\beta$-glucanase sequences of the E. coli (Accession Number: NP_417988.1) and Bacillus circulans (Park and Yun, 1999; Hakamada et al., 2002) as well as metagenomics study

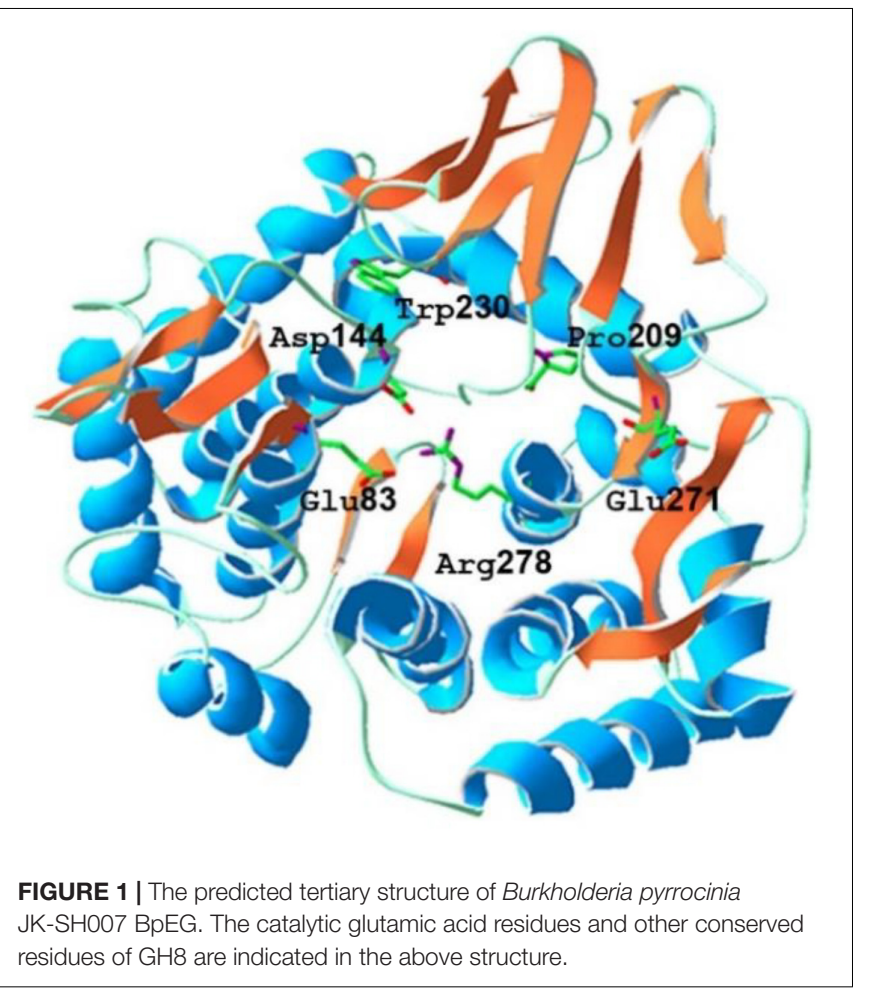

from Ladakh soil, as described previously by Bhat et al. (2013). The BpEG model structure also showed the putative catalytic residues, Glu83, and Glu271, correspond to the proton donor and acceptor (Figure 1), similar to the structure of Bacillus sp. K17 (Adachi et al., 2004). BpEG structure also showed high activity against the soluble substrate whereas it exhibited no catalytic activity against a crystalline cellulose substrate. It has also been suggested that the BpEG sequence does not contain a cellulose-binding domain.

\section{Heterologous Expression of Recombinant BpEG}

The recombinant plasmid pET32a-BpEG was transformed into the competent cells of E. coli BL21 (DE3) and this expression of recombinant BpEG was induced by the IPTG. The activity of the endo-1,4- $\beta$-glucanase of the recombinant crude enzyme solution was determined to be $7.09 \mathrm{U} / \mathrm{ml}$. The recombinant BpEG was purified from the culture supernatant of E. coli by Ni-IDA affinity chromatography. Further, we conducted the SDS-PAGE analysis under denaturing conditions, and the molecular weight of the purified recombinant BpEG was estimated to be $60 \mathrm{kDa}$ (Figure 3A). The molecular weights of the endo-1,4- $\beta$-glucanases from other species, namely Rhizopus oryzae (Murashima et al., 2002), Citrobacter farmeri A1 (Bai et al., 2016), and Ganoderma lucidum (Liu et al., 2016), were previously reported.

\section{Western Blot Analysis and Identification of the Partial Peptide Fragment}

Further characterization of the purified recombinant BpEG protein was performed using the Western blot analysis. The purified enzyme was initially separated using 12.5\% SDS-PAGE and blotted onto a polyvinylidene fluoride (PVDF) membrane in Tris-glycine-methanol buffer. Results obtained from the Western blot analysis showed a band at $60 \mathrm{kDa}$. This result was found to be consistent with the SDS-PAGE results (Figure 3B). The sequencing analysis of the above-obtained recombinant BpEG fragments using an automatic protein sequencer showed us the conserved domains AIRVYLWAGM and VPGLGVTLLP. These conservative fragments exhibited high similarity with the endo1,4- $\beta$-glucanases sequences of E. coli (Park and Yun, 1999) and Citrobacter farmeri A1 (Bai et al., 2016), which belong to GH 8.

\section{Properties of Recombinant BpEG}

In order to study the catalytic properties of recombinant $\mathrm{BpEG}$, we conducted a series of enzymatic assays with varying conditions, especially $\mathrm{pH}$ and temperatures, to study the stability of the recombinant $\mathrm{BpEG}$ protein. The recombinant BpEG exhibited the highest enzymatic activity toward CMC (100\%), followed by PASC (62.5\%), respectively. But BpEG cannot degrade crystalline cellulose and xylan (Table 1). These results suggested that BpEG was specific and had endoglucanases activity.

The CMC (Figure 5B) was used as the substrate in the subjected enzymatic assays to determine the functional properties of the recombinant BpEG protein. Results obtained from these enzymatic assays exhibited an optimum $\mathrm{pH}$ of 6 for the 


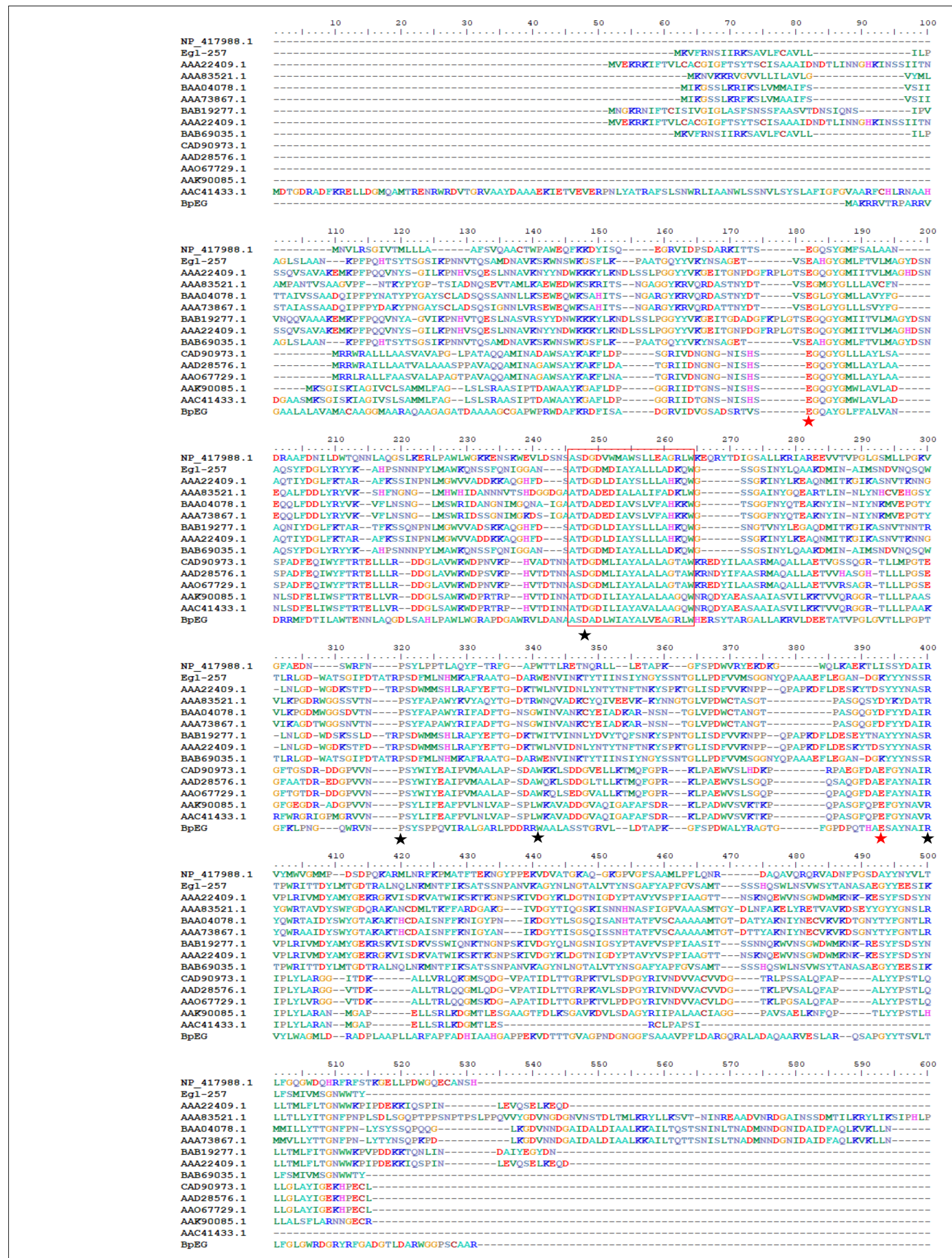

FIGURE 2 | Amino acid sequence alignment of BpEG from B. pyrrocinia JK-SH007 with the family GH8 from Escherichia coli K-12 (NP_417988.1), Bacillus circulans KSM-N257 (Egl-257) (Hakamada et al., 2002), Bacillus sp. KK-1 (AAC27700.1), Clostridium thermocellum NCIB 10682 (AAA83521.1), Clostridium josui FERM P-9684 (BAA04078.1), Clostridium cellulolyticum ATCC 35319 (AAA73867.1), Bacillus sp. No.7-M (BAB19277.1), Bacillus sp. KSM-330 (AAA22409.1), Bacillus circulans KSM-N257 (BAB69035.1), Rhizobium leguminosarum bv. trifolii ANU843 (CAD90973.1), Rhizobium leguminosarum bv. trifolii R201 (AAD28576.1), Rhizobium leguminosarum bv. trifolii 1536 (AAO67729.1), Agrobacterium tumefaciens C58 (Cereon) (AAK90085.1), and Agrobacterium tumefaciens C58 (U. North Carolina) (AAC41433.1) using the ClustalW program. The highly conserved residues and catalytic residues are indicated with black and red asterisks, respectively. Conservative motif was in red box. 


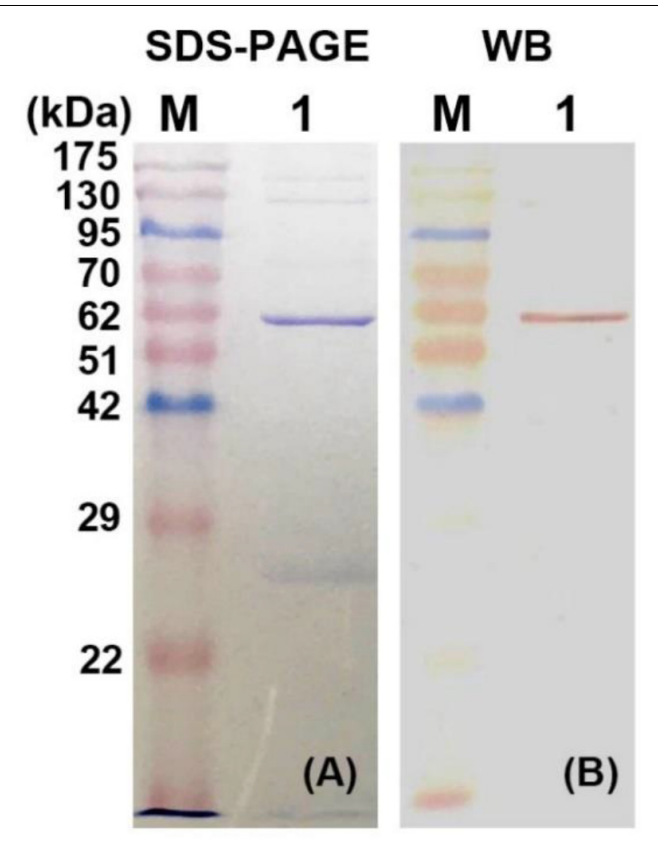

FIGURE 3 | Expression and purification of recombinant BpEG. (A) The SDS-PAGE analysis of purified recombinant BpEG. (B) Western blot analysis of purified recombinant BpEG. M, opti-protein marker/ladder (Applied Biological Materials, Inc., Canada); 1, purified endo-1,4- $\beta$-glucanase.

TABLE 1 | The substrate specificity of recombinant BpEG.

\begin{tabular}{llcl}
\hline Item & Substrate & Relative activity & Production \\
\hline Polysaccharide & CMC & $100 \%$ & Glucose \\
polymer & PASC & $56 \%$ & Glucose \\
& Avicel & 0 & NO \\
& Xylan & 0 & NO \\
Oligosaccharide & Cellopentaose & ND & $\begin{array}{l}\text { Cellotriose, cellotriose, } \\
\text { cellotetraose, glucose }\end{array}$ \\
& Cellotetraose & $N D$ & Cellotriose, glucose, \\
& & & cellobiose \\
& Cellotriose & ND & Cellotriose \\
& Cellobiose & ND & Cellobiose
\end{tabular}

ND, not determined; NO, not obtained.

recombinant BpEG (Figure 4A and Table 2). The recombinant BpEG exhibited $70 \%$ of the maximum activity between a $\mathrm{pH}$ range of 5.0 and 7.0 (Figure 4B). The optimum $\mathrm{pH}$ of the recombinant BpEG protein showed comparable results with the previously reported endo- $\beta-1,4$ glucanases from Rhizopus oryzae (Murashima et al., 2002), Eisenia foetida (Ueda et al., 2014), and G. lucidum (Liu et al., 2016), respectively. However, another study reported that endo-1,4- $\beta$-glucanases isolated from the Citrobacter farmeri A1 showed an optimum $\mathrm{pH}$ of 3.5-7.5 (Bai et al., 2016).

The activity of the recombinant BpEG was also determined at various temperatures, ranging from $10-60^{\circ} \mathrm{C}$ at an optimum $\mathrm{pH}$ of 6.0. The optimal temperature of BpEG was determined to be $35^{\circ} \mathrm{C}$ (Figure $4 \mathrm{C}$ and Table 2). The result obtained in our study is in accordance with previous reports on endo-1,4$\beta$-glucanase (rPdCel5C) conducted by Liu et al. (Liu et al., 2013). Interestingly, the recombinant BpEG also exhibited about $42 \%$ of the catalytic activity at $10^{\circ} \mathrm{C}$ (Figure 4C). That is to say, BpEG was still functional at low temperatures. Therefore, it suggested that BpEG can be regarded as a cold-adaptive enzyme. In addition, BpEG maintains approximately $80 \%$ maximal activity after the treatment at $30^{\circ} \mathrm{C}$ for $45 \mathrm{~min}$ (Figure $4 \mathrm{D}$ ). That indicated BpEG was relatively stable at low temperatures. The cold adaptability of the recombinant BpEG protein was found to be consistent with the previously reported endo-1,4- $\beta$-glucanases (Ueda et al., 2014). These results indicate that BpEG was an enzyme that adapted to a cold environment.

We have listed the previous reports on endo- $1,4-\beta$-glucanases from other species in Table 1, and few of them were appraised as cold active endo-1,4- $\beta$-glucanases. Namely, the optimal temperatures of the endo-1,4- $\beta$-glucanases isolated from the Penicillium decumbens, Citrobacter farmeri $\mathrm{A} 1$ and E. foetida were identified between the range of 30 and $50^{\circ} \mathrm{C}$, and these enzymes exhibited about $30-40 \%$ of their total catalytic activity at $10^{\circ} \mathrm{C}$ (Ueda et al., 2014; Bai et al., 2016; Liu et al., 2016). In addition, the endo-1,4- $\beta$-glucanase (RCE1) isolated from the Rhizopus oryzae also exhibited adaptability to low temperatures (Murashima et al., 2002). All these reports suggest that the cold active endo-1,4- $\beta$-glucanase had a wide range of distribution. Furthermore, previous reports showed that Burkholderia discovered in Antarctic and Arctic lichens, and the lipases of Burkholderia were determined as cold-adapted active enzymes (Table 3). Moreover, the optimal temperatures of lipases isolated from Burkholderia anthina NT15, Burkholderia sp. SYBC LIP-Y and Burkholderia sp. JXJ-16 were measured to be $30-35^{\circ} \mathrm{C}$ (Han and Chen, 2010; Jin et al., 2012; Xie et al., 2017). These results show that Burkholderia adapts to cold environments, and their basic metabolism may be sustained at low temperatures. In other words, Burkholderia is a very promising producer of cold-active enzymes.

In order to further characterize BpEG, the enzymatic activity of purified recombinant BpEG was determined to be approximately $11.2 \mathrm{Umg}^{-1}$ against the CMC substrate. The catalytic activity of BpEG was higher than that of E. coli (5.2 $\mathrm{Umg}^{-1}$ protein) (Park and Yun, 1999). Therefore, the recombinant BpEG represents a more efficient enzyme candidate with various applications, especially in the field of bioconversion. The recombinant BpEG enzymes were not found to be active against the crystalline cellulose substrates containing the 1,4$\beta$-glycosidic bonds. BpEG's inability to digest the crystalline cellulose was found to be similar to that of endo-1,4- $\beta$-glucanase $(\mathrm{BcsC})$ of glycoside hydrolase $(\mathrm{GH})$ family 8 from E. coli, Bacillus circulans strains and metagenomics study of Ladakh soil (Park and Yun, 1999; Hakamada et al., 2002; Bhat et al., 2013). However, crystalline cellulose is the major substrate for exoglucanases as reported by Han and Chen (2010) and Mahmood et al. (2013). Usually, the enzymatic hydrolysis of insoluble and crystalline cellulose substrates mainly relies on the cellulose-binding domains. Exoglucanase from S. cerevisiae has a cellulose-binding domain (Moses et al., 2005), but neither BpEG nor $\mathrm{BcsC}$ have designated cellulose-binding domains. Yet these 

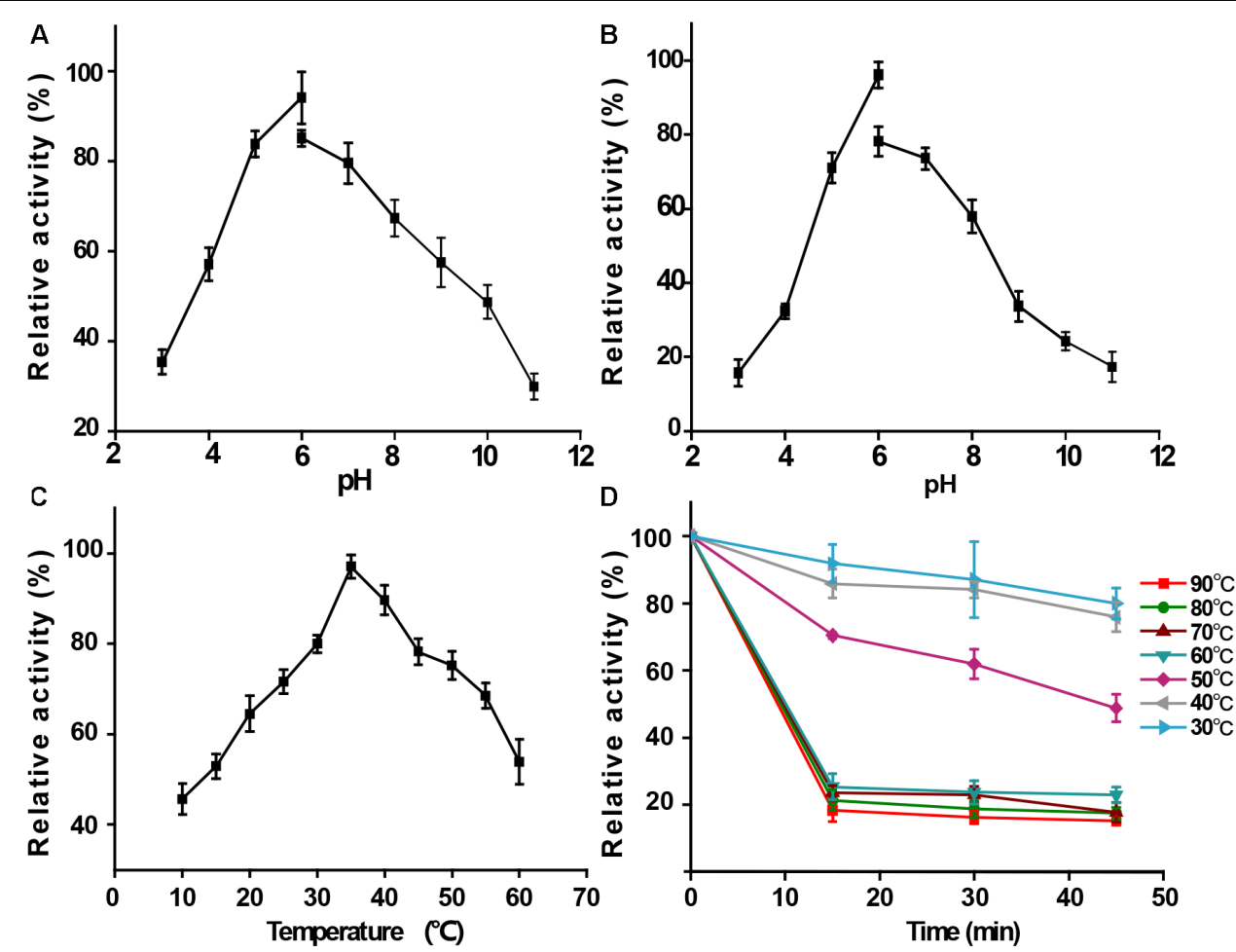

FIGURE 4 | Functional properties of purified recombinant BpEG. (A) Effect of pH on enzyme activity at $35^{\circ} \mathrm{C}$. (B) Effect of pH on enzyme stability at $35^{\circ} \mathrm{C}$. (C) Effect of temperature on enzyme activity measured at $10-60^{\circ} \mathrm{C}$. (D) Effect of temperature on enzyme stability after $15-45$ min incubation at $40-90^{\circ} \mathrm{C}$. The bars represent standard deviations.

TABLE 2 | Properties of endo-1,4- $\beta$-glucanases.

\begin{tabular}{|c|c|c|c|c|c|c|}
\hline Origin (enzyme name) & $\begin{array}{l}\text { Molecular } \\
\text { mass (kDa) }\end{array}$ & $\begin{array}{c}\text { Optimum } \\
\text { pH }\end{array}$ & $\begin{array}{c}\text { Optimum } \\
\text { temperature }\left({ }^{\circ} \mathrm{C}\right)\end{array}$ & $\begin{array}{c}\mathrm{pH} \\
\text { stability }\end{array}$ & Thermostability & References \\
\hline Burkholderia pyrrocinia JK-SH007 (BpEG)* & 43 & 6.0 & 35 & $5.0-8.0$ & $30-50^{\circ} \mathrm{C}$ & This study \\
\hline Penicillium decumbens (rPdCel5C)* & 67.6 & 4.8 & $40-50$ & $4.0-5.0$ & $30-50^{\circ} \mathrm{C}$ & Liu et al., 2013 \\
\hline Citrobacter farmeri A1 (EglC22b) ${ }^{\star}$ & 42 & 7.0 & $30-40$ & $3.5-7.5$ & $20-50^{\circ} \mathrm{C}$ & Bai et al., 2016 \\
\hline Eisenia foetida (EF-EG2)* & 50 & 5.5 & 40 & $5.0-9.0$ & $\sim 40^{\circ} \mathrm{C}$ & Ueda et al., 2014 \\
\hline Penicillium purpurogenum (KJS506) & 37 & 5.0 & 70 & $5.0-7.0$ & ND & Lee et al., 2010 \\
\hline
\end{tabular}

ND, not determined; *, cold active enzyme.

TABLE 3 | Properties of cold-active enzymes from Burkholderia.

\begin{tabular}{|c|c|c|c|c|c|c|c|}
\hline Origin & Enzyme name & $\begin{array}{l}\text { Molecular } \\
\text { mass }\end{array}$ & $\begin{array}{l}\text { Optimum } \\
\text { pH }\end{array}$ & $\begin{array}{c}\text { Optimum } \\
\text { temperature }\left({ }^{\circ} \mathrm{C}\right)\end{array}$ & $\begin{array}{c}\mathrm{pH} \\
\text { stability }\end{array}$ & Thermostability & References \\
\hline Burkholderia anthina NT15 & Lipase & $44.5 \mathrm{kDa}$ & 9.5 & 30 & ND & ND & Jin et al., 2012 \\
\hline Burkholderia sp. JXJ-16 & Lipase & ND & $8.5-9.0$ & 35 & $5.0-10.5$ & $30-60^{\circ} \mathrm{C}$ & Xie et al., 2017 \\
\hline Burkholderia pyrrocinia JK-SHOO7 & Endo-1,4- $\beta$-glucanase & $43 \mathrm{kDa}$ & 6.0 & 35 & $5.0-8.0$ & $30-50^{\circ} \mathrm{C}$ & This study \\
\hline
\end{tabular}

ND, not determined.

studies demonstrated that BpEG also belongs to the GH 8 family and showed the special endo-1,4- $\beta$-glucanase activity against the soluble cellulose substrates.
Thus, we wanted to study the mode of action of the purified recombinant BpEG. We used different substrates including $\mathrm{CMC}$ and cello-oligosaccharides of various lengths (cellobiose, 

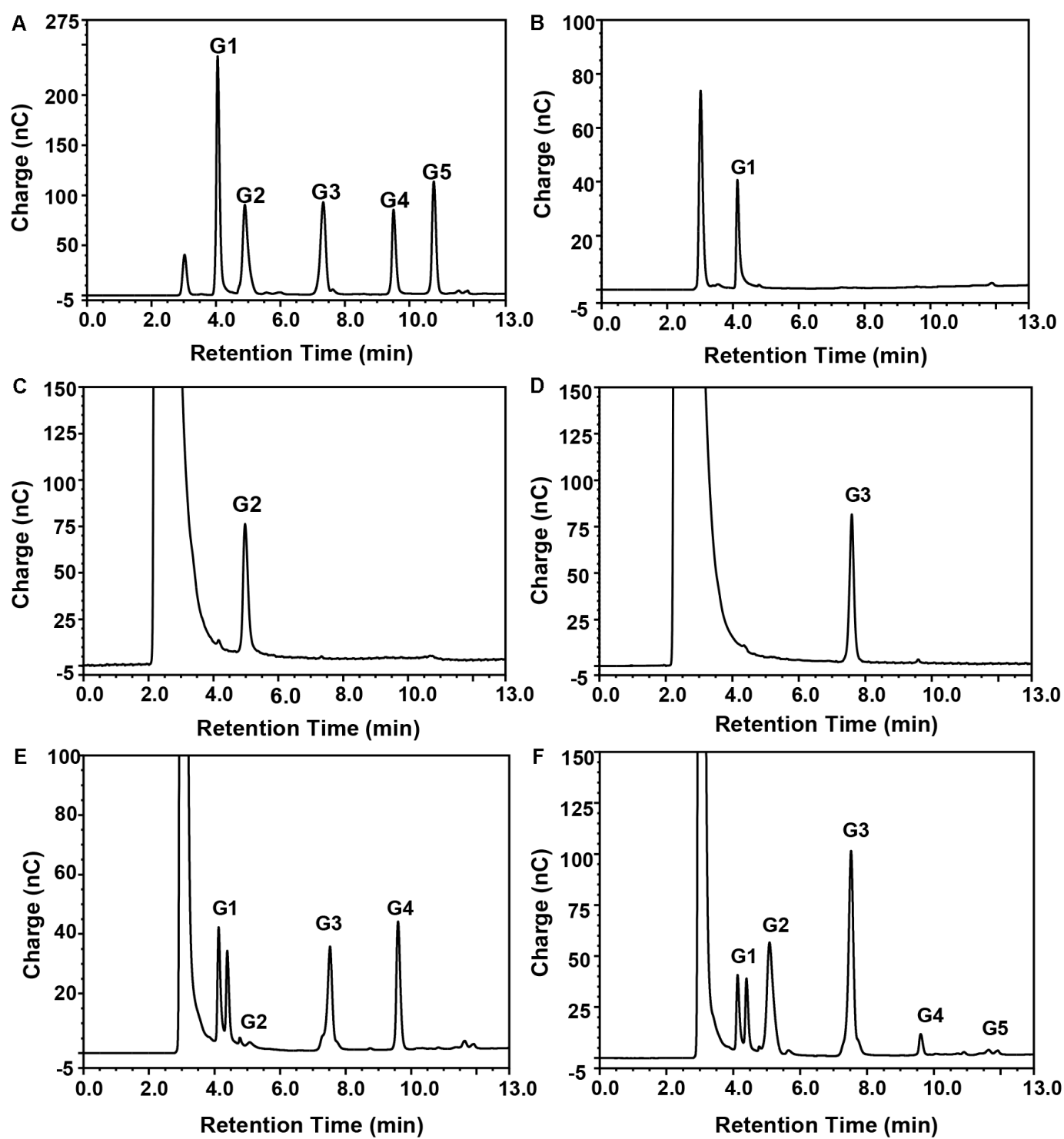

FIGURE 5 | Mode of action of purified recombinant BpEG analyzed by HPAEC-PAD. Separation of the reaction products from enzyme reactions conducted with (B) CMC-Na, (C) cellobiose, (D) cellotriose, (E) cellotetraose, or (F) cellopentaose, as described in section "Materials and Methods." Standards (A) G1, glucose; G2, cellobiose; G3, cellotriose; G4, cellotetraose; and G5, cellopentaose.

cellotriose, cellotetraose, and cellopentaose involved in 1,4$\beta$-glycosidic bonds) to study the hydrolysis rates of BpEG, and the products obtained from the enzyme hydrolysis were analyzed using HPAEC-PAD (Figure 5 and Table 1). Results obtained from the enzymatic CMC hydrolysis experiments of BpEG mostly resulted in glucose (Figure 5B). In addition, the major hydrolysis products from cellopentaose were cellotriose and cellobiose (Figure 5F). A small amount of cellotetraose and glucose production was also observed. The result suggested that BpEG randomly cut cellopentaose, as described by $\mathrm{Xu}$ et al. (2000). We also used cellotetraose as a substrate to study the mode of action of the purified recombinant BpEG. The products obtained from the hydrolysis mainly included cellotriose and glucose (Figure 5E). However, our results showed that cellotriose and cellobiose were not degraded (Figures 5C,D). Generally, cellotriose is the substrate for $\beta$-glucanase. Results obtained from all our enzyme hydrolysis experiments showed almost similar hydrolysis patterns, and the products obtained from the hydrolysis experiments of endo-1,4- $\beta$-glucanases of E. foetida (Ueda et al., 2014) were also similar. Therefore, BpEG can be considered as an endo-type 1,4- $\beta$-glucanase. These results also suggested that BpEG can degrade cello-oligosaccharides into oligosaccharides with lower polymerization degree.

In order to explore the potential application of BpEG, we used two ways to study. One way is that BpEG degrades the biomasses alone, the release of reducing sugar was limited. The yields of reducing sugars released from wheat bran, oat grain, and ginkgo leaves were $0.042 \mathrm{mg} / \mathrm{mg}, 0.046 \mathrm{mg} / \mathrm{mg}$, and $0.047 \mathrm{mg} / \mathrm{mg}$ in 
$30 \mathrm{~min}$, respectively. However, the other way is that BpEG and commercial cellulases jointly degrade the biomasses, the released reducing sugar by BpEG from different biomass was increased. The biomass of oat grain exhibited the highest yield of released reducing sugar $(100 \%, 0.22 \mathrm{mg} / \mathrm{mg})$, followed by the ginkgo leaves $(45 \%, 0.10 \mathrm{mg} / \mathrm{mg})$ and wheat bran $(32 \%, 0.071 \mathrm{mg} / \mathrm{mg})$ in $30 \mathrm{~min}$. The yields of reducing sugar from oat grain, ginkgo leaves and wheat bran increased by 5.2, 2.1 and 1.5 folds, respectively. This result is also consistent with that enzymatic hydrolysis of cellulose to glucose is a complicated process, which requires a synergistic action of cellulolytic enzymes including exo- $\beta$-1,4glucanases (EC3.2.1.91), endo- $\beta$-1,4-glucanases (EC3.2.1.4), and $\beta$-glucosidases (EC 3.2.1.21) (Sharma et al., 2016). Those results suggested that BpEG was a promising candidate in the fields of biofuel, biorefining, food and pharmaceutical industries.

\section{CONCLUSION}

In this study, we identified and reported on the highly active endo-1,4- $\beta$-glucanase (BpEG) isolated from the B. pyrrocinia JK-SH007 strain. We implemented an integrated approach by performing a sequence-based bioinformatic analysis and enzymatic hydrolysis and characterization experiments. We have successfully cloned the GC-rich (74.71\% of GC) BpEG gene. The analysis of the predicted amino acid sequence indicated that BpEG belongs to GH family 8. The BpEG gene fragment without a signal peptide coding sequence was successfully expressed in E. coli BL21 (DE3). The above-described recombinant BpEG enzyme we obtained was successfully characterized using SDSPAGE and Western blotting techniques. The stability of BpEG was investigated under various temperatures, $\mathrm{pH}$ conditions, and various cellulosic substrates. The optimum $\mathrm{pH}$ and temperature of the BpEG were found to be 6.0 and $35^{\circ} \mathrm{C}$, respectively. Interestingly, the BpEG retained $42 \%$ of its catalytic activity at $10^{\circ} \mathrm{C}$, suggesting the $\mathrm{BpEG}$ was regarded as a cold-adaptive enzyme. The recombinant BpEG enzyme can play a crucial role in

\section{REFERENCES}

Adachi, W., Sakihama, Y., Shimizu, S., Sunami, T., Fukazawa, T., Suzuki, M., et al. (2004). Crystal structure of family GH-8 chitosanase with subclass II specificity from Bacillus sp. K17. J. Mol. Biol. 343, 785-795. doi: 10.1016/j.jmb.2004.08.028

Bai, X., Yuan, X., Wen, A., Li, J., Bai, Y., and Shao, T. (2016). Cloning, expression and characterization of a cold-adapted endo-1, $4-\beta$-glucanase from Citrobacter farmeri A1, a symbiotic bacterium of Reticulitermes labralis. Peerj 4:e2679. doi: $10.7717 /$ peerj.2679

Balat, M. (2011). Production of bioethanol from lignocellulosic materials via the biochemical pathway: a review. Energy Convers. Manag. 52, 858-875. doi: 10.1016/j.enconman.2010.08.013

Bhat, A., Riyaz-Ul-Hassan, S., Ahmad, N., Srivastava, N., and Johri, S. (2013). Isolation of cold-active, acidic endocellulase from Ladakh soil by functional metagenomics. Extremophiles 17, 229-239. doi: 10.1007/s00792-012-0510-8

Bianchetti, C. M., Brumm, P., Smith, R. W., Dyer, K., Hura, G. L., Rutkoski, T. J., et al. (2013). Structure, dynamics, and specificity of endoglucanase D from Clostridium cellulovorans. J. Mol. Biol. 425, 4267-4285. doi: 10.1016/j.jmb.2013. 05.030

Borrull, A., Lopez-Martinez, G., Miro-Abella, E., Salvado, Z., Poblet, M., Cordero-Otero, R., et al. (2016). New insights into the physiological various industrial processes, as it can exhibit significant catalytic activity even at lower temperatures. Thus, the identification of cold-adaptive cellulases, like BpEG, constitutes an important step in the development of a low-temperature dependent industrial process that can achieve synchronous saccharification and fermentation (SSF) process. Additionally, BpEG can degrade various cello-oligosaccharides into oligosaccharides with lower polymerization degrees. That suggested BpEG is a promising candidate to product oligosaccharides for the food industry and pharmaceutical industry. The cold-adaptive recombinant BpEG enzyme can significantly influence various temperaturedependent industrial applications by simultaneously enhancing the cellulose hydrolysis rates.

\section{DATA AVAILABILITY STATEMENT}

The datasets generated for this study can be found in the GenBank database/MH733823.

\section{AUTHOR CONTRIBUTIONS}

FC, WQ, and JY designed the experiments. FC, XW, and JR performed the experiments. FC and XW analyzed the data. FC, AS, WQ, D-WL, and JY wrote the manuscript.

\section{FUNDING}

This work was financially supported by the Jiangsu Agricultural Science and Technology Independent Innovation Fund (CX16-1005), the Chinese State Forestry Administration Special Research Program for Forestry Sectors Beneficial to the Public (No. 201304404), the Shanghai Science and Technology Agriculture Key Project (2014:5-6), and the Priority Academic Program Development of Jiangsu Higher Education Institutions (PAPD).

state of Saccharomyces cerevisiae during ethanol acclimation for producing sparkling wines. Food Microbiol. 54, 20-29. doi: 10.1016/j.fm.2015. 11.001

Hakamada, Y., Endo, K., Takizawa, S., Kobayashi, T., Shirai, T., Yamane, T., et al. (2002). Enzymatic properties, crystallization, and deduced amino acid sequence of an alkaline endoglucanase from Bacillus circulans. BBA-Gen. Subj. 1570, 174-180. doi: 10.1016/s0304-4165(02)00194-0

Han, Y. J., and Chen, H. Z. (2010). Biochemical characterization of a maize stover beta-exoglucanase and its use in lignocellulose conversion. Bioresour. Technol. 101, 6111-6117. doi: 10.1016/j.biortech.2010.02.108

Heinze, T., El Seoud, O. A., and Koschella, A. (2018). "Production and characteristics of cellulose from different sources," in Cellulose Derivatives, eds R. S. Langer, and N. A. Peppas, (Cham: Springer International Publishing), 1-38. doi: 10.1007/978-3-319-73168-1_1

Huang, J. W., Liu, W., Lai, H. L., Cheng, Y. S., Zheng, Y., Li, Q., et al. (2016). Crystal structure and genetic modifications of FI-CMCase from Aspergillus aculeatus F-50. Biochem. Biophys. Res. Commun. 478, 565-572. doi: 10.1016/j.bbrc.2016. 07.101

Jin, D. Y., Wang, Z. H., Cao, J., and Yu, L. J. (2012). Purification and characterization of a novel cold-adapted lipase from Burkholderia anthina NT15. Afr. J. Microbiol. Res. 6, 6075-6080. 
Khalili Ghadikolaei, K., Gharechahi, J., Haghbeen, K., Akbari Noghabi, K., Hosseini Salekdeh, G., and Shahbani Zahiri, H. (2018). A cold-adapted endoglucanase from camel rumen with high catalytic activity at moderate and low temperatures: an anomaly of truly cold-adapted evolution in a mesophilic environment. Extremophiles 22, 315-326. doi: 10.1007/s00792-0180999-6

Laemmli, U. K. (1970). Cleavage of structural proteins during the assembly of the head of bacteriophage T4. Nature 227, 680-685. doi: 10.1038/227680a0

Lee, K. M., Jeya, M., and Joo, A. R. (2010). Purification and characterization of a thermostable endo- $\beta$-1,4-glucanase from a novel strain of Penicillium purpurogenum. Enzyme Microb. Technol. 46, 206-211. doi: 10.1016/j. enzmictec.2009.11.002

Liu, G., Li, Q., Shang, N., Huang, J. W., Ko, T. P., Liu, W., et al. (2016). Functional and structural analyses of a 1,4- $\beta$-endoglucanase from Ganoderma lucidum. Enzyme Microb. Technol. 86, 67-74. doi: 10.1016/j.enzmictec.2016.01.013

Liu, G., Qin, Y., Hu, Y., Gao, M., Peng, S., and Qu, Y. (2013). An endo-1,4$\beta$-glucanase PdCel5C from cellulolytic fungus Penicillium decumbens with distinctive domain composition and hydrolysis product profile. Enzyme Microb. Technol. 52, 190-195. doi: 10.1016/j.enzmictec.2012.12.009

Mahmood, R. T., Asad, M. J., Mehboob, N., Mushtaq, M., Gulfraz, M., Asgher, M., et al. (2013). Production, purification, and characterization of exoglucanase by Aspergillus fumigatus. Appl. Biochem. Biotechnol. 170, 895-908. doi: 10.1007/ s12010-013-0227-x

Miller, G. L. (1959). Use of dinitrosalicylic acid reagent for determination of reducing sugar. Anal. Chem. 31, 426-428. doi: 10.1021/ac60147a030

Moses, S. B., Otero, R. R., and Pretorius, I. S. (2005). Domain engineering of Saccharomyces cerevisiae exoglucanases. Biotechnol. Lett. 27, 355-362. doi: 10.1007/s10529-005-1014-8

Murashima, K., Nishimura, T., Nakamura, Y., Koga, J., Moriya, T., Sumida, N., et al. (2002). Purification and characterization of new endo-1,4- $\beta$ - $d$-glucanases from Rhizopus oryzae. Enzyme Microb. Technol. 30, 319-326. doi: 10.1016/ s0141-0229(01)00513-0

Na, H. B., Jung, W. K., Jeong, Y. S., Kim, H. J., Kim, S. K., Kim, J., et al. (2015). Characterization of a GH family $8 \beta-1,3-1,4$-glucanase with distinctive broad substrate specificity from Paenibacillus sp. X4. Biotechnol. Lett. 37, 657-658. doi: 10.1007/s10529-014-1724-x

Park, Y. W., and Yun, H. D. (1999). Cloning of the Escherichia coli endo-1,4-Dglucanase gene and identification of its product. Mol. Gen. Genet. 261, 236-241. doi: $10.1007 / \mathrm{s} 004380050962$

Rafique, M. M., and Rehman, S. (2017). National energy scenario of Pakistan Current status, future alternatives, and institutional infrastructure: An overview. Renew. Sustain. Energy Rev. 69, 156-167. doi: 10.1016/j.rser.2016. 11.057

Reis, V. R., Bassi, A. P. G., Cerri, B. C., Almeida, A. R., Carvalho, I. G. B., Bastos, R. G., et al. (2018). Effects of feedstock and co-culture of Lactobacillus fermentum and wild Saccharomyces cerevisiae strain during fuel ethanol fermentation by the industrial yeast strain PE-2. AMB Expr. 8:23. doi: 10.1186/ s13568-018-0556-9

Ren, J. H., Ye, J. R., Liu, H., Xu, X. L., and Wu, X. Q. (2011). Isolation and characterization of a new Burkholderia pyrrocinia strain JK-SH007 as a potential biocontrol agent. World J. Microbiol. Biotechnol. 27, 2203-2215. doi: 10.1007/ s11274-011-0686-6

Schulein, M. (1997). Enzymatic properties of cellulases from Humicola insolens. J. Biotechnol. 57, 71-81. doi: 10.1016/s0168-1656(97)00090-4

Sharma, A., Tewari, R., Rana, S. S., Soni, R., and Soni, S. K. (2016). Cellulases: classification, methods of determination and industrial applications. Microbiol. Biot. 179, 1346-1380. doi: 10.1007/s12010-016-2070-3

Silveira, M. H., Aguiar, R. S., Siika-aho, M., and Ramos, L. P. (2014). Assessment of the enzymatic hydrolysis profile of cellulosic substrates based on reducing sugar release. Bioresour. Technol. 151, 392-396. doi: 10.1016/j.biortech.2013.09.135
Towbin, H., Staehelin, T., and Gordon, J. (1979). Electrophoretic transfer of proteins from polyacrylamide gels to nitrocellulose sheets - procedure and some applications. PNAS 76, 4350-4354. doi: 10.1073/pnas.76.9.4350

Ueda, M., Ito, A., Nakazawa, M., Miyatake, K., Sakaguchi, M., and Inouye, K. (2014). Cloning and expression of the cold-adapted endo-1,4- $\beta$-glucanase gene from Eisenia fetida. Carbohydr. Polym. 101, 511-516. doi: 10.1016/j.carbpol. 2013.09.057

Ueda, M., Noda, K., Nakazawa, M., Miyatake, K., Ohki, S., Sakaguchi, M., et al. (2008). A novel anti-plant viral protein from coelomic fluid of the earthworm Eisenia foetida: purification, characterization and its identification as a serine protease. Comp. Biochem. Physiol. B Biochem. Mol. Biol. 151, 381-385. doi: 10.1016/j.cbpb.2008.08.005

Uppugundla, N., Da, C. S. L., Chundawat, S. P., Yu, X., Simmons, B., Singh, S., et al. (2014). A comparative study of ethanol production using dilute acid, ionic liquid and AFEX ${ }^{\mathrm{TM}}$ pretreated corn stover. Biotechnol. Biofuels 7 , 1-14.

Wang, K., Luo, H., Bai, Y., Shi, P., Huang, H., Xue, X., et al. (2014). A thermophilic endo-1,4- $\beta$-glucanase from Talaromyces emersonii CBS394.64 with broad substrate specificity and great application potentials. Appl. Microbiol. Biot. 98, 7051-7060. doi: 10.1007/s00253-014-5680-0

Wang, Y., Yuan, H., Wang, J., and Yu, Z. (2009). Truncation of the cellulose binding domain improved thermal stability of endo- $\beta$-1,4-glucanase from Bacillus subtilis JA18. Bioresour. Technol. 100, 345-349. doi: 10.1016/j.biortech. 2008.06.001

Wu, X. D., Zhang, J. S., Xu, E. N., Liu, Y. H., Cheng, Y. L., Addy, M., et al. (2016). Microbial hydrolysis and fermentation of rice straw for ethanol production. Fuel 180, 679-686. doi: 10.1016/j.fuel.2016.04.087

Xie, Y. T., Dai-Ming, Z., Shi, H. Q., Zhang, B. H., and Han-Quan, L. I. (2017). Optimization of enzyme production conditions and enzymatic properties of cold-adapted and organic solvent-tolerant lipase from Burkholderia sp.JXJ-16. Sci. Technol. Food Indus. 38, 165-171.

Xu, B., Hellman, U., Ersson, B., and Janson, J. C. (2000). Purification, characterization and amino-acid sequence analysis of a thermostable, low molecular mass endo- $\beta$-1, 4-glucanase from blue mussel, Mytilus edulis. Eur. J. Biochem. 267, 4970-4977. doi: 10.1046/j.1432-1327.2000.01533.x

Xu, Y., Fan, L., Wang, X., Yong, Q., and Yu, S. Y. (2013). Simultaneous separation and quantification of linear Xylo- and Cello-Oligosaccharides mixtures in Lignocellulosics processing products on high-performance anion-exchange chromatography coupled with pulsed amperometric detection. Bioresources 8 , 3247-3259.

Yuan, B. H., Cai, Y. J., Liao, X. R., Yun, L. H., Zhang, F., and Zhang, D. B. (2010). Isolation and identification of a cold-adapted lipase producing strain from decayed seeds of Ginkgo biloba L. and characterization of the lipase. Afr. J. Biotechnol. 9, 2661-2667.

Zhao, Z. Y., Zuo, J., Fan, L. L., and Zillante, G. (2011). Impacts of renewable energy regulations on the structure of power generation in China - A critical analysis. Renew. Energy 36, 24-30. doi: 10.1016/j.renene.2010. 05.015

Conflict of Interest: The authors declare that the research was conducted in the absence of any commercial or financial relationships that could be construed as a potential conflict of interest.

Copyright ( $\odot 2020$ Chen, Ye, Sista Kameshwar, Wu, Ren, Qin and Li. This is an open-access article distributed under the terms of the Creative Commons Attribution License (CC BY). The use, distribution or reproduction in other forums is permitted, provided the original author(s) and the copyright owner(s) are credited and that the original publication in this journal is cited, in accordance with accepted academic practice. No use, distribution or reproduction is permitted which does not comply with these terms. 